\title{
European Society of Gastrointestinal Endoscopy - Establishing the key unanswered research questions within gastrointestinal endoscopy
}

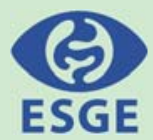

Authors

Institutions
Colin J. Rees ${ }^{1}$, Wee Sing Ngu' ${ }^{1}$, Jaroslaw Regula ${ }^{2}$, Raf Bisschops ${ }^{3}$, Adrian Saftoiu ${ }^{4}$, Evelien Dekker ${ }^{5}$, lan Gralnek ${ }^{6}$, Mihai Ciocirlan ${ }^{7}$, Mario Dinis-Ribeiro ${ }^{8}$, Rodrigo Jover ${ }^{9}$, Søren Meisner ${ }^{10}$, Cristiano Spada ${ }^{11}$, Cesare Hassan ${ }^{12}$, Roland Valori ${ }^{13}$, Tomas Hucl ${ }^{14}$, Olivier Le Moine ${ }^{15}$, Dirk Domagk ${ }^{16}$, Michal F. Kaminski ${ }^{2,17}$, Michael Bretthauer ${ }^{17}$, Matthew D. Rutter ${ }^{18}$, Lars Aabakken ${ }^{19}$, Thierry Ponchon ${ }^{20}$, Paul Fockens ${ }^{5}$, Peter D. Siersema ${ }^{21}$

Institutions are listed at end of article. submitted 26. February 2016 accepted after revision 15. March 2016

\section{Bibliography}

Dol http://dx.doi.org/

10.1055/s-0042-110398

Published online: 2.8 .2016

Endoscopy 2016; 48: 884-891

(c) Georg Thieme Verlag KG

Stuttgart · New York

ISSN 0013-726X

Corresponding author

Colin J. Rees, MD

Department of

Gastroenterology

South Tyneside District Hospital

Harton Lane

South Shields

Newcastle upon Tyne

Tyne and Wear NE34 OPL

United Kingdom

Fax: +44-191-4041366

colin.rees@stft.nhs.uk
Background and study aim: Gastrointestinal endoscopy is a rapidly evolving research field. The European Society of Gastrointestinal Endoscopy (ESGE) plays a key role in shaping opinion and endoscopy activity throughout Europe and further afield. Establishing key unanswered questions within the field of endoscopy and prioritizing those that are important enables researchers and funders to appropriately allocate resources.

Methods: Over 2 years, the ESGE Research Committee gathered information on research priorities and refined them through a modified Delphi approach. Consultations were held with the ESGE Governing Board and Quality Improvement Committee to identify important unanswered questions. Research workshops were held at the 21st United European Gastroenterology Week. Research questions were refined by the ESGE Research Committee and Governing Board, compiled into an online survey, and distributed to all

\section{Introduction \\ $\nabla$}

Gastrointestinal endoscopy is a diverse and rapidly evolving field. Modern advances in technology have revolutionized patient care through techniques such as endoscopic retrograde cholangiopancreatography (ERCP) with sphincterotomy, endoscopic polypectomy, endoscopic ultrasonography (EUS), and endoscopic variceal ligation. Advancement in technology has unearthed gaps in existing knowledge that can only be answered with robust research. In this era of evidencebased medicine, quality research is important as it helps to inform policies and guidelines. Governing bodies such as the National Institute for Health and Care Excellence in the United Kingdom (UK) rely on research to benchmark standards and guidelines [1].

In Europe, approximately $€ 40$ per person per year is spent in the field of biomedical and health re-
ESGE members, who were invited to rank each question by priority.

Results: The final questionnaire yielded 291 responses from over 60 countries. The three countries with the highest response rates were Spain, Italy, and United Kingdom. Most responders were from teaching hospitals (62\%) and were specialist endoscopists (51\%). Responses were analyzed with weighted rankings, resulting in prioritization of 26 key unanswered questions. The top ranked generic questions were: 1) How do we define the correct surveillance interval following endoscopic diagnosis? 2) How do we correctly utilize advanced endoscopic imaging? 3) What are the best markers of endoscopy quality? Conclusion: Following this comprehensive process, the ESGE has identified and ranked the key unanswered questions within the field of gastrointestinal endoscopy. Researchers, funders, and journals should prioritize studies that seek to answer these important questions.

search [2]. In the UK, the Medical Research Council spent $£ 771.8$ million on government-funded medical research in 2014/15 [3]. In 2015, over 3500 published articles were identified (using PubMed search) that included the term "gastrointestinal endoscopy" in their titles or abstracts. In previous years, pharmaceutical and medical device industries have been accused of monopolizing the research agenda and not addressing questions about treatments that are held in high regard by patients and clinicians [4-6]. This has led to the creation of organizations such as The James Lind Alliance, which was set up with Priority Setting Partnerships to identify unanswered research questions that patients, carers, and clinicians feel are important [7].

Establishing research priorities is important to allow resources to be channeled into the most important research that will benefit patients. Studies that have the ability to answer important clin- 
ical questions impacting practice and influencing policy often require multicenter collaborative research to optimize validity [8]. The European Society of Gastrointestinal Endoscopy (ESGE) was established in 1964 and among its aims is the promotion of interest, teaching, and research in the field of gastrointestinal endoscopy. It promotes international exchange of endoscopy data and technical advances, and supports large-scale international studies. The Research Committee of the ESGE has the mandate for establishing, discussing, and promoting clinical research in digestive endoscopy at a broad European level.

Over a 2-year period, the ESGE has sought to define the key unanswered questions within the field of gastrointestinal endoscopy. The ESGE believes that these should become priority areas for future endoscopy research and would encourage researchers within the field of gastrointestinal endoscopy to make these areas a priority. The ESGE would also encourage funding organizations to prioritize funding towards research that seeks to answer these questions.

\section{Methods}

$\nabla$

The modified Delphi approach is a well-established methodological process for obtaining consensus expert opinion and is used widely in health research [9]. Over a 2-year period, a three-step process was utilized to establish the key unanswered questions within gastrointestinal endoscopy. In Round 1, preparatory work was performed by creating a list of key unanswered research questions generated from the ESGE Research Committee, Governing Board, Quality Improvement Committee, and Quality Improvement working groups. In addition, research workshops were held during the 21st United European Gastroenterology Week to obtain feedback from individual ESGE members regarding research priorities.

In Round 2, the ESGE Research Committee and Governing Board refined the questions. Research questions were then divided into seven sections according to endoscopy procedure type - upper gastrointestinal, lower gastrointestinal, small bowel, and hepatopancreaticobiliary endoscopy, which was further divided into EUS and ERCP; generic priorities and other cross-cutting themes or questions were also identified. Specific research questions were generated for each section and the wording of questions was revised over several iterations. The final number of questions in each section differed according to the size of the clinical field. Questions that overlapped were consolidated. Through these processes, a total of 58 key unanswered questions were identified (৫ Table 1).

In Round 3, all questions were incorporated into a simple online questionnaire with a ranking system, allowing participants to rank each question by order of priority using SurveyMonkey (www.surveymonkey.com) (see Appendix e1, available online). An online link was sent out via email to all ESGE members, including board members. Members were asked to rank the priority of each research question using a scale of 1 for highest priority to 5 for lowest priority. A weighting was applied to the questionnaire results to generate a final priority list. Higher weighting was given to scores with the highest priority (e.g. a rating of 1 received a weighted score of 5 , a rating of 5 received a weighted score of 1 ), and the weightings were summated to give a score, which was used to rank the research questions. In addition, respondents were also asked to provide demographic information, namely their country of origin, type of hospital, and job title.
Completion of the survey was voluntary, with an iPad prize offered via a random draw as an incentive to participate.

\section{Results}

\section{$\nabla$}

A total of 291 responses to the online survey were received, with participants working in over 60 countries. The three countries with the most respondents were Spain, Italy, and the UK. The majority of respondents were from teaching hospitals (62\%), followed by community hospitals (23\%), and private clinics (15\%). Most respondents were specialist endoscopists (51\%), followed by general gastroenterologists who performed endoscopy (43\%), and trainees (6\%). A weighted ranking matrix was used to analyze the results of the survey and to determine the priority of all of the key unanswered questions. As a result, 58 key unanswered questions were narrowed down to a total of 26 ( Table 2 ).

Endoscopists from different countries or with different levels of practice did not rank the priorities significantly differently. The leading generic priority and priorities for upper and lower gastrointestinal endoscopy, respectively, all related to optimizing surveillance: How do we define the correct surveillance interval following initial endoscopic diagnosis? What is the correct surveillance strategy for atrophic gastritis and metaplastic gastritis? What is the optimal surveillance of patients following colonoscopic polypectomy? For small-bowel endoscopy, the question "How should we investigate occult or acute gastrointestinal bleeding following normal upper and lower gastrointestinal endoscopy?" was the number one priority. For EUS "How do we optimally diagnose and manage cystic pancreatic tumors?" and for ERCP "What are the roles for magnetic resonance cholangiopancreatography, ERCP, and EUS?" were ranked as most important. Additionally "How do we define the interface between endotherapy and gastrointestinal surgery?" was defined as the most important cross-cutting theme.

\section{Discussion \\ $\nabla$}

This is the first large international collaborative effort to identify and prioritize key unanswered questions within the field of gastrointestinal endoscopy. These results provide a clear framework for ESGE researchers to determine important research questions and studies, and will help funders to identify key future research priorities that have the greatest relevance to improving patient care.

\section{Generic priorities}

Surveillance intervals for endoscopy remain a contentious issue, with some disease processes having been researched more than others. Colorectal cancer, inflammatory bowel disease, and postpolypectomy surveillance are examples of conditions where some evidence has allowed for guidelines to be developed [10, 11]. However, there is still a lack of high evidence level studies, and this applies to a myriad of other disease processes including gastric polyps, gastritis, and Barrett's esophagus. Advanced endoscopic imaging modalities, such as narrow-band imaging, I-Scan (Pentax Endoscopy, Tokyo, Japan), Fuji Intelligent Color Enhancement (Fujinon, Tokyo, Japan), autofluorescence imaging, and confocal laser endomicroscopy, have yet to establish their role in gastrointestinal endoscopy [12-14]. Adenoma detection rate is currently regarded as the most important surrogate indicator of 
Table 1 Completed list of perceived key unanswered research questions in gastrointestinal endoscopy.

\section{GENERIC PRIORITIES}

1 How do we define the correct surveillance interval following initial endoscopic diagnosis?

2 How do we measure and improve the experience of patients undergoing gastrointestinal endoscopy?

3 How do we correctly utilize advanced endoscopic imaging?

$4 \quad$ What are the best markers of endoscopy quality?

$5 \quad$ What are the best ways to train endoscopists?

\section{UPPER GASTROINTESTINAL ENDOSCOPY}

6 What is the correct surveillance strategy for Barrett's esophagus?

7 How do we optimize eradication therapy for Helicobacter pylori?

8 What is the correct surveillance strategy for atrophic gastritis and metaplastic gastritis?

9 When can anticoagulant medication be restarted following gastrointestinal bleeding?

10 What is the correlation between esophageal motility and extraesophageal symptoms?

11 What are the dysplasia rates in Barrett's surveillance in general endoscopy practice?

12 What are the rates of intestinal metaplasia in the stomach in general European endoscopy practice?

13 Could visualization of the papilla of Vater be used as a measure for a complete and high quality endoscopy?

14 What is the relation between inspection time during upper gastrointestinal endoscopy and diagnostic yield?

15 How do biopsies influence management of conditions of the upper gastrointestinal tract?

16 What is the role of advanced imaging in dysplasia detection in Barrett's esophagus, squamous cancer detection in high risk patients or intestinal metaplasia in the stomach?

17 Can automated image analysis replace biopsies and guide the management of the patient in Barrett's esophagus, squamous cancer detection in high risk patients or intestinal metaplasia in the stomach?

18 Can training modules improve image interpretation and lesion recognition for endoscopists?

\section{LOWER GASTROINTESTINAL ENDOSCOPY}

19 What is the optimal surveillance of patients following colonoscopic polypectomy?

20 How do we translate optical diagnosis into standard clinical practice?

21 What is the importance of sessile serrated polyps?

22 Can we deliver unsedated colonoscopy as patient-centered care?

23 What are the relative risks and complications of post colonoscopy colorectal cancer in patients receiving propofol sedation compared to those receiving conscious or no sedation?

24 What is the optimal strategy for colitis surveillance?

25 Can surveillance interval be adjusted depending upon both patient factors and the quality of the endoscopy?

26 Can further polyp characterization (sessile serrated lesions, number of polyps, and size of polyps) be a better predictor of interval cancer rates than adenoma detection rate?

27 What are the risks and benefits of leaving smaller polyps in place in older persons? Is it possible to define an age cutoff where the risks exceed the benefits?

28 Is immersion training superior to the current approach?

29 How to optimize bowel prep and does poor bowel prep correlate with post colonoscopy colorectal cancer?

30 When is it safe to undertake therapy without discontinuing antithrombotics?

31 Can we define key performance indicators for therapy?

\section{SMALL-BOWEL ENDOSCOPY}

32 How should we investigate occult or acute gastrointestinal bleeding following normal upper and lower gastrointestinal endoscopy?

33 Should we perform capsule endoscopy or deep enteroscopy?

34 How can capsule endoscopy be used therapeutically?

35 How do we define the quality of bowel preparation?

36 What is the role of capsule endoscopy in inflammatory bowel disease?

37 What is the optimal imaging modality for the small bowel?

38 Can we develop automatic reading analysis algorithms?

39 What is the role of double camera capsule endoscopy of the entire gastrointestinal tract?

40 Which is superior - capsule endoscopy or device-assisted enteroscopy in patients with overt upper gastrointestinal bleeding?

41 What is the long term impact of capsule endoscopy in different patient cohorts with regard to a) health outcomes and b) cost-benefit analysis?

42 How do we use other clinical markers to optimize the indications for capsule endoscopy and small-bowel enteroscopy?

43 How do we differentiate masses from bulges seen at capsule endoscopy?

44 How do we measure the therapeutic benefit of enteroscopy?

\section{HEPATOPANCREATICOBILIARY ENDOSCOPY - EUS}

45 How do we optimally diagnose and manage cystic pancreatic tumors?

46 How do we improve noninvasive diagnostic methods (e. g. contrast-enhanced endoscopic ultrasonography, 3D-reconstruction) for differential diagnosis of pancreatic cancer and inflammatory diseases?

47 Is there value in defining landmarks in endoscopic ultrasonography for staging of gastrointestinal tumors?

\section{HEPATOPANCREATICOBILIARY ENDOSCOPY - ERCP}

48 Where is precut indicated and safe?

49 How to manage benign pancreatic strictures?

50 What are the roles for magnetic resonance cholangiopancreatography, endoscopic retrograde cholangiopancreatography and endoscopic ultrasonography?

51 Is endoscopic cholangiopancreatography-radiofrequency therapy effective for palliative cancer treatment?

52 What is the optimal approach to access the biliary tree in patients with altered anatomy? 


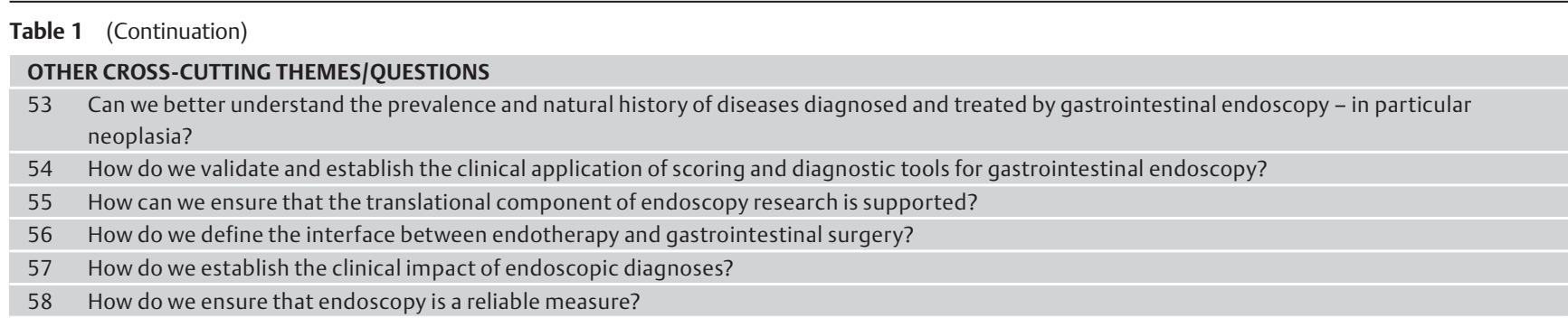

\begin{tabular}{|c|c|c|}
\hline Rank & GENERIC PRIORITIES & Score \\
\hline 1 & How do we define the correct surveillance interval following initial endoscopic diagnosis? & 439 \\
\hline 2 & How do we correctly utilize advanced endoscopic imaging? & 367 \\
\hline 3 & What are the best markers of endoscopy quality? & 353 \\
\hline \multicolumn{3}{|c|}{ UPPER GASTROINTESTINAL ENDOSCOPY } \\
\hline 1 & What is the correct surveillance strategy for atrophic gastritis and metaplastic gastritis? & 500 \\
\hline 2 & What is the correct surveillance strategy for Barrett's esophagus? & 469 \\
\hline 3 & When can anticoagulant medication be restarted following gastrointestinal bleeding? & 440 \\
\hline 4 & $\begin{array}{l}\text { What is the role of advanced imaging in dysplasia detection in Barrett's esophagus, squamous cancer detection in high risk patients } \\
\text { or intestinal metaplasia in the stomach? }\end{array}$ & 387 \\
\hline 5 & Can training modules improve image interpretation and lesion recognition for endoscopists? & 366 \\
\hline \multicolumn{3}{|c|}{ LOWER GASTROINTESTINAL ENDOSCOPY } \\
\hline 1 & What is the optimal surveillance of patients following colonoscopic polypectomy? & 566 \\
\hline 2 & What is the importance of sessile serrated polyps? & 556 \\
\hline 3 & $\begin{array}{l}\text { Can further polyp characterization (sessile serrated lesions, number of polyps, and size of polyps) be a better predictor of interval } \\
\text { cancer rates than adenoma detection rate? }\end{array}$ & 370 \\
\hline 4 & $\begin{array}{l}\text { What are the risks and benefits of leaving smaller polyps in place in older persons? Is it possible to define an age cutoff where the risks } \\
\text { exceed the benefits? }\end{array}$ & 335 \\
\hline 5 & Can surveillance interval be adjusted depending upon both patient factors and the quality of the endoscopy? & 310 \\
\hline \multicolumn{3}{|c|}{ SMALL-BOWEL ENDOSCOPY } \\
\hline 1 & How should we investigate occult or acute gastrointestinal bleeding following normal upper and lower gastrointestinal endoscopy? & 626 \\
\hline 2 & What is the optimal imaging modality for the small bowel? & 424 \\
\hline 3 & How can capsule endoscopy be used therapeutically? & 361 \\
\hline 4 & Should we perform capsule endoscopy or deep enteroscopy? & 307 \\
\hline 5 & Can we develop automatic reading analysis algorithms? & 298 \\
\hline \multicolumn{3}{|c|}{ HEPATOPANCREATICOBILIARY ENDOSCOPY - EUS } \\
\hline 1 & How do we optimally diagnose and manage cystic pancreatic tumors? & 311 \\
\hline 2 & $\begin{array}{l}\text { How do we improve noninvasive diagnostic methods (e. g. contrast-enhanced endoscopic ultrasonography, 3D-reconstruction) } \\
\text { for differential diagnosis of pancreatic cancer and inflammatory diseases? }\end{array}$ & 286 \\
\hline \multicolumn{3}{|c|}{ HEPATOPANCREATICOBILIARY ENDOSCOPY - ERCP } \\
\hline 1 & $\begin{array}{l}\text { What are the roles for magnetic resonance cholangiopancreatography, endoscopic retrograde cholangiopancreatography, and } \\
\text { endoscopic ultrasonography? }\end{array}$ & 355 \\
\hline 2 & What is the optimal approach to access the biliary tree in patients with altered anatomy? & 310 \\
\hline 3 & Where is precut indicated and safe? & 299 \\
\hline \multicolumn{3}{|c|}{ OTHER CROSS-CUTTING THEMES / QUESTIONS } \\
\hline 1 & How do we define the interface between endotherapy and gastrointestinal surgery? & 318 \\
\hline 2 & $\begin{array}{l}\text { Can we better understand the prevalence and natural history of diseases diagnosed and treated by gastrointestinal endoscopy - } \\
\text { in particular neoplasia? }\end{array}$ & 314 \\
\hline 3 & How do we validate and establish the clinical application of scoring and diagnostic tools for gastrointestinal endoscopy? & 304 \\
\hline
\end{tabular}

quality in colonoscopy and a low adenoma detection rate has been shown to correlate with higher interval colorectal cancers [15-18]. However, other markers that may reflect improvements in endoscopy quality have not, to date, been researched in detail.

\section{Upper gastrointestinal endoscopy}

Atrophic gastritis and metaplastic gastritis are precursor lesions for gastric cancer but endoscopy surveillance for this group of patients is poorly studied. Studies from Korea, UK, and elsewhere in Europe have advocated screening intervals of $1-3$ years for high-risk subjects but randomized controlled trials (RCTs) are still required [19-21]. Barrett's esophagus is a precursor for esophageal adenocarcinoma but there are currently no completed RCTs that support the practice of screening in these patients. The management of patients on anticoagulants with acute gastrointestinal bleeding can be challenging, as several factors such as type of anticoagulant, bleeding severity, and thrombotic risk have to be considered. There are no RCTs available to guide clinical practice. However, a retrospective cohort study of 1329 patients found that restarting warfarin after 7 days decreased the mortality and thromboembolism risk without increasing the risk of bleeding [22]. The role of advanced imaging in dysplasia detection in Barrett's esophagus or squamous cancer and intestinal metaplasia in the stomach is still under-researched, and 
more RCTs are required [23-25]. Training modules including simulators have been shown to accelerate the learning of practical skills in gastrointestinal endoscopy [26]. However, no large RCTs have examined the role of training modules in improving image interpretation and lesion recognition among endoscopists.

\section{Lower gastrointestinal endoscopy}

To date, no large randomized trials have assessed the benefit of surveillance in post-polypectomy patients. Current guidelines that are available focus on epidemiological data, screening studies, and expert opinion [10]. Sessile serrated polyps represent $15 \%-20 \%$ of all serrated polyps [27]. In recent years, the pathway from serrated polyp to colorectal cancer has been described but clinical data are still lacking, with many unanswered questions concerning the transition of serrated polyps to cancer [28]. Adenoma detection rate has been shown to be an independent predictor of interval cancer rates [16-18]. However, further polyp characterization and its relationship with interval cancer rate have yet to be studied. The relationship between the benefits and risks of leaving small polyps in older patients has not been studied. Colonoscopy surveillance that takes into account individual patient factors and quality of endoscopy is also underreported.

\section{Small-bowel endoscopy}

Patients with occult or overt gastrointestinal bleeding with negative upper gastrointestinal endoscopy and colonoscopy can present a diagnostic challenge. Capsule endoscopy, push or single-/double-balloon enteroscopy, computed tomography (CT) angiography, radionuclide imaging, and small-bowel follow through have all been described as modalities to investigate this group of patients [29]. However, there are a lack of large randomized trials to advocate the use of one modality over the other. Furthermore, the optimal imaging modality for the small bowel is unclear. Successful imaging of the small bowel depends on the use of available and appropriate radiology to answer a particular clinical question. A range of imaging techniques including smallbowel barium study, abdominal ultrasound, CT enteroclysis, and magnetic resonance imaging (MRI) enteroclysis are available, but more studies are required to determine the role of each modality in different disease processes.

Capsule endoscopy is becoming increasingly recognized as a diagnostic tool for the small bowel $[30,31]$. However its role in therapeutics is unclear and more research will be required to determine this. As the role of capsule endoscopy becomes more established, studies comparing the benefits and risks of deep enteroscopy against capsule endoscopy also need to be performed. Automatic reading analysis algorithms have begun to be developed for capsule endoscopy, but will require more progress before being adopted for general use $[32,33]$.

\section{Hepatopancreaticobiliary endoscopy - EUS}

Increased use of abdominal cross-sectional imaging has allowed for increased detection of pancreatic cystic tumors. However, these lesions remain difficult to classify without surgical resection, and a lack of evidence into the management of these lesions makes them difficult to treat [34]. EUS and MRI are accepted techniques for pancreatic imaging [35], but more research needs to be done to investigate ways of improving these methods for diagnosing and staging patients with pancreatic cancer. Research is currently under way to improve EUS imaging capabilities, including elastography and contrast enhancement, and also to in- crease the accuracy of sampling procedures based on EUS-guided fine-needle aspiration [36,37].

\section{Hepatopancreaticobiliary endoscopy - ERCP}

Magnetic resonance cholangiopancreatography (MRCP), ERCP, and EUS are imaging modalities that are used to investigate pancreaticobiliary disease. The role of each modality has not been clearly established. A review found EUS to be more sensitive than ERCP in diagnosing chronic pancreatitis, and superior to MRCP in the detection of microlithiasis and in evaluating pancreatic divisum [38]. However, there are a lack of large randomized trials comparing each modality. Cap-assisted ERCP and doubleballoon enteroscopic ERCP have been shown in small series to show promising results in patients with altered anatomy [39, 40]. Large scale RCTs are still required to investigate this in further detail. Precut sphincterotomy is an alternative used when standard methods of biliary access have failed. Most studies have reported high cannulation rates of more than $90 \%$, but complication rates of $13.9 \%$ have been reported with common bile duct diameters of $\leq 4 \mathrm{~mm}[41,42]$.

\section{Cross-cutting themes / questions}

The emergence of endotherapy has added to the arsenal of minimally invasive techniques available to manage patients with perforations, leaks, and fistulae that may have required surgical intervention in the past [43]. Although these may only be applicable to a select group of patients, more studies are required to compare the outcomes of endotherapy techniques with conventional gastrointestinal surgery. There are large gaps in the understanding of the prevalence and natural progression of other types of gastrointestinal neoplasia, which should be studied.

Scoring and diagnostic tools are being used increasingly in gastrointestinal endoscopy. The Glasgow-Blatchford Bleeding Score and Rockall Score are examples of scoring tools established to assess the need for treatment in patients with acute upper gastrointestinal bleeding. In particular, the Glasgow-Blatchford Bleeding Score was developed 15 years ago, but only a handful of studies have looked at its validity in discriminating between patients at risk of bleeding [44-46].

\section{The next step}

The current study provides insight into the research priorities of ESGE members. However, translation of these priorities into more specific research questions will require discussion and planning. It is hoped that this study will provide a stimulus for researchers to address these questions and develop collaborative research. Moreover, it is hoped that research themes that have been identified as priorities by the ESGE will receive prioritization from funding organizations. Finally, a gastrointestinal endoscopy research question that has been identified as a priority based on a gap in current evidence is more likely to lead to publication of the research in a high quality journal. Although no list can incorporate all important research questions, this study aimed to identify the most important areas through a wide ranging of consultation of all ESGE members.

This is the first international piece of work established to set the priorities for research within the field of gastrointestinal endoscopy. Similar approaches have been adopted in other areas of medicine, including public mental health care $[47,48]$, palliative cancer care [49], colorectal surgery [50], and breast cancer care [51]. Similarly, the American Society of Colon and Rectal Surgeons utilized a modified Delphi approach to highlight key re- 
search priorities for colorectal surgery [52]. Other specialties that have prioritized key research questions within their field include pediatric palliative care in America [53], elderly care physicians in Canada [54], and gynecologists in Australia [55]. The World Health Organization recently published the key research priorities that were identified to improve global newborn health and prevent stillbirths by 2025 [56]. There is a lack of evidence to illustrate the impact or outcomes of setting research priorities, partly as these processes do not normally cover impact measurement or analysis of outcomes [57].

Having completed this work, the ESGE will seek to disseminate these results widely to stakeholders in order to encourage prioritization of these areas. Researchers themselves should be encouraged to develop research that addresses these unanswered questions. The ESGE will disseminate these priorities within member societies. Where large-scale collaboration is required, this should be supported and facilitated by the ESGE. Secondly, it is important that funders should be encouraged to prioritize research that addresses these areas. It is also important to note that research priorities often can only be answered by long-term studies, which in turn require longitudinal funding, and funders should thus be encouraged to consider this. The ESGE will seek to engage with international funders such as the European Union and then with funding bodies within member countries. Some countries have horizon scanning organizations, which aim to collate priority areas across the whole field of biomedical research. It is important that where these organizations exist they are advised about the priorities in endoscopy research. Finally, the ESGE will engage with industry to encourage commercial partners to align their priorities with these unanswered questions.

\section{Conclusion}

This list of leading research priorities was generated using a systematic, transparent, and inclusive approach across multiple countries. The research priorities cover a wide range of important topics, and it is hoped that these findings will be used to encourage researchers, funders, and journals to prioritize research that addresses these areas within the field of gastrointestinal endoscopy.

\section{Appendix e1}

European Society of Gastrointestinal Endoscopy research priorities questionnaire.

Competing interests: R. Bisschops has received consultancy fees from Boston Scientific (2015); speaker's fees from Covidien (2009-2016) and Norgine (2015); speaker's fee and hands-on training sponsorship from Olympus Europe (2013 - 2014); consultancy fees, speaker's fee, and research support from Pentax Europe (2008-2016) and Fujifilm (2013-2016); support from FWO Flanders; research support from Cook Medical (20152016); hands-on training sponsorship from Erbe (2013-2015); and an editorial fee from Thieme Verlag as coeditor of Endoscopy. E. Dekker receives a research grant and equipment on loan from Olympus, equipment on loan from Fujifilm and medical advice from Tillots. M. Dinis-Ribeiro receives funding from Thieme Verlag for editorial work for the journal Endoscopy. His department has also received support from Olympus in relation to a teaching protocol (from August 2014 to July 2015). P. Fockens has a consulting role during 2016 with Fujifilm, Olympus, Medtronic and
Cook. R. Jover's department has received research grants from MSD and he has an advisory role with Norgine. M. F. Kaminski has a lecturing and teaching role for Olympus, Poland. S. Meisner has a consultancy role with Olympus Europa and SE \& CO. KG. T. Ponchon receives advisory board member's fee from Olympus, Ipsen Pharma, Boston Scientific in 2014 and 2015; speaker's fee from Fujiflim, Ipsen Pharma in 2014 and 2015 and from Covidien in 2014; advisory board member's fee from Cook medical in 2014; training support from Ferring in 2014; speaker's fee from Olympus in 2014 and 2015; research support from Boston Scientific, Olympus in 2014 and 2015. C. Rees receives research funding from Olympus, Aquiland and arc Medical. M. Rutter's department receives research funding from Olympus for a colitis surveillance trial (2014 to present). A. Saftoiu had a consulting role with Mediglobe Corporation $\mathrm{f}$ in 2015 and 2016 and own stock with Medinsys from 2012 til 2016; receives an editorial fee for Ultrasound International Open (UIO) from Thieme Verlag. P. D. Siersema's department has received research grants from EndoStim, Cook Medical, Dr. Falk Pharma Benelux, Motus GI, Yakult, Pentax, World Cancer Research Fund. He is a consultant for EndoChoice USA, Endostim USA, Motus GI Israel and Medi-Globe Germany. He also conducts paid editorial work for the journal Endoscopy. C. Spada has received training support from Covidien, Alfa Wasserman and Norgine. R. Valori is a director of Quality Solutions for Healthcare LLP, a company providing consultancy for improving quality in healthcare, and of AnderVal Ltd., a company providing endoscopy skills training. L. Aabakken, M. Bretthauer, M. Ciocirlan, D. Domagk, I. Gralnek, T. Hucl, O. Le Moine, W. S. Ngu and J. Regula have no competing interests.

\section{Institutions}

${ }^{1}$ Department of Gastroenterology, South Tyneside District Hospital, South Shields, United Kingdom

${ }^{2}$ Department of Gastroenterology, Hepatology and Oncology, Medical Centre for Postgraduate Education and the Maria Sklodowska-Curie Memorial Cancer Centre and Institute of Oncology, Warsaw, Poland

${ }^{3}$ Department of Gastroenterology, University Hospital Leuven, Leuven, Belgium

${ }^{4}$ Research Centre of Gastroenterology and Hepatology, University of Medicine and Pharmacy of Craiova, Craiova, Romania

${ }^{5}$ Department of Gastroenterology and Hepatology, Academic Medical Centre, University of Amsterdam, Amsterdam, The Netherlands

${ }^{6}$ Institute of Gastroenterology and Liver Diseases, Ha'Emek Medical Centre, Afula, Israel

${ }^{7}$ Carol Davila University of Medicine and Pharmacy, Gastroenterology and Hepatology Clinic, Fundeni Clinical Institute, Bucharest, Romania

8 Department of Gastroenterology, Instituto Portugues de Oncologia, Porto,

Portugal

${ }^{9}$ Department of Gastroenterology, Hospital General Universitario, Alicante, Spain

${ }^{10}$ Gastrointestinal Unit, Department of Surgery, University Hospital Herlev, Copenhagen, Denmark

${ }^{11}$ Digestive Endoscopy Unit, Catholic University, Rome, Italy

${ }^{12}$ Gastroenterology Unit, Nuovo Regina Margherita Hospital, Rome, Italy

${ }^{13}$ Department of Gastroenterology, Gloucestershire Royal Hospital, Gloucester, United Kingdom

${ }^{14}$ Department of Gastroenterology and Hepatology, Institute for Clinical and Experimental Medicine, Prague, Czech Republic

${ }^{15}$ Department of Gastroenterology, Hepatopancreatology and Digestive Oncology, Université Libre de Bruxelles, Erasme Hospital, Brussels, Belgium

${ }^{16}$ Department of Medicine, Josephs-Hospital Warendorf, Academic Teaching Hospital, University of Münster, Warendorf, Germany

${ }^{17}$ Department of Health Management and Health Economics and KG Jebsen Center for Colorectal Cancer Research, University of Oslo, Oslo, Norway

${ }^{18}$ Department of Gastroenterology, University Hospital of North Tees, Stockton-on-Tees, Cleveland, United Kingdom

${ }^{19}$ Department of Transplantation Medicine, Oslo University Hospital, Oslo, Norway

${ }^{20}$ Department of Digestive Diseases, Hospital Edouard Herriot, Lyon, France

${ }^{21}$ Department of Gastroenterology and Hepatology, Radboud University Medical Center, Nljmegen, The Netherlands 


\section{References}

1 National Institute for Health Care and Excellence. Available from: https://www.nice.org.uk/about/what-we-do

2 Berghmans S, Bisagni A, Bouillon R et al. A stronger biomedical research for a better European future - White paper II. Report No.: European Medical Research Councils. 2011. Available from: http://www.esf.org/ fileadmin/Public_documents/Publications/emrc_wpII.pdf. Accessed: 2015 Nov 29

3 Medical Research Council: Facts \& Figures. 2015. Available from: http://www.mrc.ac.uk/about/spending-accountability/facts/. Accessed: 2015 Nov 29

4 Delaney $B$. Is society losing control of the medical research agenda? BMJ 2006; 332: $1063-1064$

5 Patsopoulos NA, Ioannidis JPA, Analatos AA. Origin and funding of the most frequently cited papers in medicine: database analysis. BMJ 2006; 332: 1061 - 1064

6 Tallon D, Chard J, Dieppe P. Relation between agendas of the research community and the research consumer. Lancet 2000; 355: 2037-2040

7 James Lind Alliance. Available from: http://www.jla.nihr.ac.uk. Accessed: 2015 Nov 29

8 Rothwell PM. Factors that can affect the external validity of randomized controlled trials. PLoS Clin Trials 2006; 1: e9

9 Jones J, Hunter D. Consensus methods for medical and health services research. BMJ 1995; 311: 376-380

10 Hassan C, Quintero E, Dumonceau J-M et al. Post-polypectomy colonoscopy surveillance: European Society of Gastrointestinal Endoscopy (ESGE) Guideline. Endoscopy 2013; 45: 842-851

11 National Institute for Health and Care Excellence. Colonoscopic surveillance for preventing colorectal cancer in adults with ulcerative colitis, Crohn's disease or adenomas. Available from: https://www.nice. org.uk/guidance/cg118. Accessed: 2015 Nov 29

12 Nagorni A, Bjelakovic G, Petrovic B. Narrow band imaging versus conventional white light colonoscopy for the detection of colorectal polyps. Cochrane Database Syst Rev 2012; 1: CD008361

13 Moriichi K, Fujiya M, Sato R et al. Back-to-back comparison of autofluorescence imaging (AFI) versus high resolution white light colonoscopy for adenoma detection. BMC Gastroenterol 2012; 12: 75

14 Karstensen JG, Klausen PH, Saftoiu A et al. Molecular confocal laser endomicroscopy: a novel technique for in vivo cellular characterization of gastrointestinal lesions. World J Gastroenterol 2014; 20: 7794 - 7800

15 Lee TJ, Rutter MD, Blanks RG et al. Colonoscopy quality measures: experience from the NHS Bowel Cancer Screening Programme. Gut 2012; 61: 1050-1057

16 Kaminski MF, Regula J, Kraszewska $E$ et al. Quality indicators for colonoscopy and the risk of interval cancer. N Engl J Med 2010; 362: $1795-1803$

17 Corley $D A$, Jensen $C D$, Marks AR et al. Adenoma detection rate and risk of colorectal cancer and death. N Engl J Med 2014; 370: 1298-1306

18 Le Clercq CMC, Bouwens MWE, Rondagh EJA et al. Postcolonoscopy colorectal cancers are preventable: a population-based study. Gut 2014; 63: 957-963

19 Park YH, Kim N. Review of atrophic gastritis and intestinal metaplasia as a premalignant lesion of gastric cancer. J cancer Prev 2015; 20: 2540

20 Dinis-Ribeiro M, Areia M, de Vries AC et al. Management of precancerous conditions and lesions in the stomach (MAPS): guideline from the European Society of Gastrointestinal Endoscopy (ESGE), European Helicobacter Study Group (EHSG), European Society of Pathology (ESP), and the Sociedade Portuguesa. Endoscopy 2012; 44: 74-94

21 Whiting JL, Sigurdsson A, Rowlands DC et al. The long term results of endoscopic surveillance of premalignant gastric lesions. Gut 2002; 50: $378-381$

22 Qureshi W, Mittal C, Patsias I et al. Restarting anticoagulation and outcomes after major gastrointestinal bleeding in atrial fibrillation. Am J Cardiol 2014; 113: 662-668

23 Almond LM, Barr H. Advanced endoscopic imaging in Barrett's oesophagus. Int J Surg 2012; 10: 236-241

24 Serrano M, Kikuste I, Dinis-Ribeiro M. Advanced endoscopic imaging for gastric cancer assessment: new insights with new optics? Best Pract Res Clin Gastroenterol 2014; 28: 1079-1091

25 So J, Rajnakova A, Chan $Y$-H et al. Endoscopic tri-modal imaging improves detection of gastric intestinal metaplasia among a high-risk patient population in Singapore. Dig Dis Sci 2013; 58: 3566 - 3575
26 Ekkelenkamp VE, Koch AD, de Man RA et al. Training and competence assessment in GI endoscopy: a systematic review. Gut 2016; 65: 607-615

27 Goldstein NS, Bhanot P, Odish E et al. Hyperplastic-like colon polyps that preceded microsatellite-unstable adenocarcinomas. Am J Clin Pathol 2003; 119: $778-796$

28 Szylberg $£$, Janiczek M, Popiel A et al. Serrated polyps and their alternative pathway to the colorectal cancer: a systematic review. Gastroenterol Res Pract 2015; 2015: 573814

29 Kim BSM, Li BT, Engel A et al. Diagnosis of gastrointestinal bleeding: a practical guide for clinicians. World J Gastrointest Pathophysiol 2014; 5: $467-478$

30 Sidhu R, Sanders DS, Morris AJ et al. Guidelines on small bowel enteroscopy and capsule endoscopy in adults. Gut 2008; 57: 125-136

31 Pennazio M, Spada C, Eliakim $R$ et al. Small-bowel capsule endoscopy and device-assisted enteroscopy for diagnosis and treatment of smallbowel disorders: European Society of Gastrointestinal Endoscopy (ESGE) Clinical Guideline. Endoscopy 2015; 47: 352 - 376

32 Maciura L, Bazan JG. Granular computing in mosaicing of images from capsule endoscopy. Nat Comput 2015; 14: 569-577

33 Khan T, Shrestha R, Imtiaz MS et al. Colour-reproduction algorithm for transmitting variable video frames and its application to capsule endoscopy. Healthcare Technol Lett 2015; 2: $52-57$

34 Chandwani R, Allen PJ. Cystic neoplasms of the pancreas. Annu Rev Med 2016; 67: 45-57

35 Petrone MC, Arcidiacono PG. New strategies for the early detection of pancreatic cancer. Expert Rev Gastroenterol Hepatol 2016; 10: 157 159

36 Săftoiu A, Dietrich CF, Vilmann P. Contrast-enhanced harmonic endoscopic ultrasound. Endoscopy 2012; 44: 612-617

37 Chen G, Liu S, Zhao Yet al. Diagnostic accuracy of endoscopic ultrasoundguided fine-needle aspiration for pancreatic cancer: a meta-analysis. Pancreatology 2013; 13: 298-304

38 Ashkar M, Gardner TB. Role of endoscopic ultrasound in pancreatic diseases: a systematic review. Minerva Gastroenterol Dietol 2014; 60: $227-245$

$39 \mathrm{Ki} \mathrm{HS}$, Park $\mathrm{CH}$, Jun $\mathrm{CH}$ et al. Feasibility of cap-assisted endoscopic retrograde cholangiopancreatography in patients with altered gastrointestinal anatomy. Gut Liver 2015; 9: 109-112

40 Cho S, Kamalaporn P, Kandel G et al. "Short" double-balloon enteroscope endoscopic retrograde cholangiopancreatography in patients with a surgically altered upper gastrointestinal tract. Can J Gastroenterol 2011; 25: 615-619

41 Lopes L, Dinis-Ribeiro M, Rolanda C. Safety and efficacy of precut needle-knife fistulotomy. Scand J Gastroenterol 2014; 49: 759- 765

42 Mammen A, Haber G. Difficult biliary access: advanced cannulation and sphincterotomy technique. Gastrointest Endosc Clin N Am 2015; 25: 619-630

43 Talbot M, Yee G, Saxena P. Endoscopic modalities for upper gastrointestinal leaks, fistulae and perforations. ANZ J Surg. In press 2016. DOI: 10.1111/ans.13355

44 Blatchford O, Murray WR, Blatchford M. A risk score to predict need for treatment for upper-gastrointestinal haemorrhage. Lancet (London, England) 2000; 356: 1318-1321

45 Schiefer M, Aquarius $M$, Leffers $P$ et al. Predictive validity of the Glasgow Blatchford Bleeding Score in an unselected emergency department population in continental Europe. Eur J Gastroenterol Hepatol 2012; 24: $382-387$

46 Chandra S, Hess EP, Agarwal D et al. External validation of the GlasgowBlatchford Bleeding Score and the Rockall Score in the US setting. Am J Emerg Med 2012; 30: 673-679

47 Wykes T, Haro JM, Belli SR et al. Mental health research priorities for Europe. Lancet Psychiatry 2015; 2: 1036-1042

48 Forsman AK, Wahlbeck $K$, Aarø $L E$ et al. Research priorities for public mental health in Europe: recommendations of the ROAMER project. Eur J Public Health 2015; 25: 249-254

49 Sigurdardottir KR, Haugen DF, van der Rijt CCD et al. Clinical priorities, barriers and solutions in end-of-life cancer care research across Europe. Report from a workshop. Eur J Cancer 2010; 46: 1815-1822

50 Tiernan J, Cook A, Geh I et al. Use of a modified Delphi approach to develop research priorities for the association of coloproctology of Great Britain and Ireland. Colorectal Dis 2014; 16: 965 -970

51 Eccles SA, Aboagye EO, Ali S et al. Critical research gaps and translational priorities for the successful prevention and treatment of breast cancer. Breast Cancer Res 2013; 15: R92 
52 Burt CG, Cima RR, Koltun WA et al. Developing a research agenda for the American Society of Colon and Rectal Surgeons: results of a delphi approach. Dis Colon Rectum 2009; 52: 898-905

53 Baker JN, Levine DR, Hinds PS et al. Research priorities in pediatric palliative care. J Pediatr 2015; 167: 467-470.e3

54 Farrell B, Tsang C, Raman-Wilms L et al. What are priorities for deprescribing for elderly patients? Capturing the voice of practitioners: a modified delphi process. PLoS One 2015; 10: e0122246
55 Rogers PAW, D'Hooghe TM, Fazleabas A et al. Priorities for endometriosis research: recommendations from an international consensus workshop. Reprod Sci 2009; 16: 335-346

56 Yoshida S, Martines J, Lawn JE et al. Setting research priorities to improve global newborn health and prevent stillbirths by 2025. J Glob Health 2016; 6: 010508

57 Viergever RF, Olifson S, Ghaffar A et al. A checklist for health research priority setting: nine common themes of good practice. Health Res Policy Syst 2010; 8: 36

\section{Appendix e1}

online content viewable at:

http://dx.doi.org/10.1055/s-0042-110398 